\title{
Globalization and the Political Economy of the Brazilian Federal University
}

\author{
João dos Reis Silva Júnior'1, Eric K. Spears², Alan Victor Pimenta ${ }^{3}$ \\ ${ }^{1}$ Department of Education, Federal University of São Carlos, São Carlos, Brazil \\ ${ }^{2}$ Department of History and Geography, Georgia College, Milledgeville, USA \\ ${ }^{3}$ Department of Education, Federal University of São Carlos, São Carlos, Brazil \\ Email: joaodosreissilvajr@gmail.com
}

Received 1 July 2014; revised 6 August 2014; accepted 8 September 2014

Copyright (C) 2014 by authors and OALib.

This work is licensed under the Creative Commons Attribution International License (CC BY). http://creativecommons.org/licenses/by/4.0/

(c) (i) Open Access

\begin{abstract}
The purpose of this research is to explain how Brazilian higher education becomes a commodity of global capitalism through a focus on institutional culture change, which transforms academic independence toward a model of corporate-sponsored applied research. Brazilian federal universities are invested in S.T.E.M. education and are instruments in the country's twenty-first century hegemonic aspirations. This national development strategy has ramifications for the humanities, fine arts, and social sciences. Applied science and public-private partnerships (PPP) have irreversibly changed the trajectory of the Brazilian public university and its relationship to global capitalism. This research examines these changes to higher education and Brasília's broader political agenda through a critical political economy perspective.
\end{abstract}

\section{Keywords}

Globalization, Academic Mobility, Hegemony, Brazil Scientific Mobility Program

Subject Areas: Economics, Education

\section{Introduction}

Globalization has distorted the way in which people perceive the worth of academic mobility. In Brazil, cultural exchange is no longer appreciated as an intrinsic value to liberal learning. International academic mobility is instead seen as a national strategic interest. In the United States, international education is prioritized as tertiary export economy. NAFSA, the leading international educators association, reports that international students contributed \$20 million to the US economy in 2011 [1]. Governments and universities increasingly view foreign students and scholars as valuable intellectual capital, which fosters global competition and spurs local economic development. This standpoint is increasingly true in Brazil, which regionally constitutes $5.5 \%$ of the world's student and scholar mobility. Overall, Latin America now sends $75 \%$ of its students to North America and 
Western Europe [2]. Brazil is presently at the forefront of this mobility trend.

Brazil's growth in academic mobility surprisingly occurred during the Great Global Recession (2008-2014). Brazil's surge in student mobility is all the more reason why we should heed William L. Gertz's advice that "any discussion related to global academic mobility must be seen within the context of the current worldwide financial crisis" [3]. The recessed economies of North America and Western Europe have also been too eager to receive students and researchers as a means of revenue. International student revenue offsets sequestered funds and budget cuts that have plagued higher education since 2008, such as in the United States. Incongruously, the BRICS (Brazil, Russia, India, China, and South Africa) weathered the global financial storm with resiliency. In fact, the BRICS implemented historic "stimulus packages" to send their academic talent abroad as a part of national development strategies to hedge their political and economic influence in a multipolar world. BRICS investment in social capital through academic mobility is specifically designed to counteract the United States and the European Union's hegemonic political and economic influence. The BRICS aim to redefine the multipolar world system hinged on their own economic expansion and scientific innovation. These countries, and in particular, Brazil, recognize their future economic sway rests in the talented minds of student and faculty researchers.

It is in this spirit of a dynamic market-driven global political economy that we, the authors, critically examine the changes to Brazilian higher education vis-à-vis the ebbs and flows of global capitalism and national politics. We specifically investigate the Brazilian federal university system as it restructures itself to send students abroad in S.T.E.M. (Science, Technology, Engineering, and Math) areas through a public-private partnership (PPP) national scholarship program called the Brazil Scientific Mobility Program (formerly known as Brazil Science Without Borders (BSMP)). The BSMP sends undergraduate and postgraduate students for one year of study, research, and internships in North America, the European Union, Australia and South Korea. We argue that these initiatives are in direct response to national economic development strategies aimed at increasing Brazil's political position in the world. Brazil's engagement with neoliberalism compels its federal universities to disproportionately invest in S.T.E.M. and other applied studies, which subsequently undermine funding in other social science, humanities, and fine arts disciplines.

This investigation examines these changes to the Brazilian federal university system by placing it within a contemporary political economy framework. The study originates with Brazil's national economic restructuring program called the Plano Real in 1994 through its rise as a present-day BRICS actor. This conceptual analysis demonstrates that Brazil's changing political economy has significant implications for the country's higher education system that once enjoys more disciplinary egalitarianism and financial autonomy from the more deterministic external market forces operating at national and global scales.

\section{Contextualizing Higher Education in the Brazilian Political Economy}

It was only three decades ago that Brazil endured the "lost decade" of quadruple digit hyperinflation, political transition to civilian rule, and temporary currencies. Yet Brazil is noticeably experiencing one of its largest economic expansions in its five-hundred year history. Brazil experienced an unprecedented $7.5 \%$ economic growth in 2010 and, despite its slow down in 2014 to about 3\% of growth, the South American giant remains the seventh largest economy in the world [4]. Brazilian demographics, however, reflect a more complicated and paradoxical picture of the country's political economy. Brazil's younger population (14 to 21 years of age) has been severely affected by a $17 \%$ unemployment rate, which disproportionately affects women more than men (13\% of young people are unemployed and $23 \%$ of young women are without work) [5]. This labor concentration is more evident in Brazilian cities where the urbanization rate is $87 \%$-making the country one of the most densely populated urban societies [6]. The per capita GDP in Brazil is US \$11,900 and despite the high unemployment rates, the country is still ranked as the sixth largest market labor in the world [6].

Brazil is nevertheless a country of uneven development, with the highest concentrations of population, income, and infrastructure found in the southeastern cities and states. The division between the urban and rural spheres is notable, but the gap between the "haves" and "have-nots" in urban areas is demarcated even more sharply on the social landscape. The social welfare programs aimed at eradicating poverty during President Luiz Inácio da Silva's (Lula) administration in the early 2000s raised the wages of low-income people but did little to solve the systemic problems that undermine Brazil's collective social capital.

Public spending on primary and secondary education is still lower than in the other top ten largest economies (5\% of GDP, ranked 55 in the world) [6]. The most recent attempts to integrate a heterogeneous population in more competitive and public universities and with affirmative action policies have also exposed racial and social 
inequality in Brazil. According to a report published in the ReVista: The Harvard Review of Latin America (2012), only 14.4\% of people of African descent (18 - 24 years olds) were enrolled in higher education in 2009 [7]. This finding further suggests that funding in Brazilian higher education is not only disproportionate by discipline (with S.T.E.M. fields getting higher yields) but that minorities are also not the beneficiaries of a national economic strategy focused on innovation. Academic mobility is mostly reserved for the upper middle and higher classes in Brazil.

\section{The Brazilian Federal University}

Brazilian higher education was crafted by the invention of the federal university system in the 1950s. Public universities have since been revered as the nation's educational hallmark and recognized as leaders in research and innovation. In fact, the maturation of the Brazilian public university continued even during the "lost decade" of the 1980s, when the country's quadruple-digit hyperinflation and tempestuous political transition from military dictatorship to civilian rule made daily life uncertain. The federal university system was insulated from global and national economics in the 1980s. The introduction of democracy in the late 1980s and a new currency, the real, in 1994 prompted further educational advancement under President Fernando Henrique Cardoso.

Cardoso, a trained sociologist and critical theorist, garnered political capital from his fellow academics for the new currency and restructuring plan called the Plano Real, which also fostered neoliberal expansion throughout Brazil. This political support from Brazil's academe gave Cardoso intellectual credibility on the national stage and paved the way for another restructuring program called the Master Plan for State Reform in 1995. The "master plan" enabled Cardoso to promote public-private partnerships (PPPs) as a means of economic development. This endeavor also established a new economic rationale of efficiency in both public and private spheres. Economic efficiency was not maximized under the military dictatorship, which promoted import substitution industries (ISI) and protectionism of Brazilian industry. Cardoso's new trajectory of PPPs matched government funds with private investment while simultaneously achieving maximum efficiency in the allocation of human resources. Cardoso's government changed the course of the federal university and, to paraphrase Harvey (1996), served as an activist in creating a good business climate and competitor in the global political economy [8]. This adopted practice encouraged new forms of strategic planning that incorporated PPP cooperation and research in the applied sciences.

The early 1990s was a period of deliberate national economic restructuring, which ultimately placed universities on a track of irreversible reforms. Former presidents Fernando Henrique Cardoso (1995-2002), Luiz Inácio Lula da Silva (2003-2010), and the current president, Dilma Rousseff (2011-present), each began to view the Brazilian federal university as strategic driver of economic development. The set of institutional reforms implemented by the Plano Real created a favorable environment for PPPs to operate higher education. Cardoso defended this new approach to governance by explaining, “... in this sense, the reform of the state provides incentives for the formal rationalization of the public machine and the criteria for open competition, to the detriment of the powerful bureaucratic records” [9]. This public policy tactic in Brasília transformed the federal university system from a recursive academic culture to one centered on competitive applied research and innovation. The Brazilian federal university, in essence, became an actor in the national economy.

The notion that the federal university is an agent of innovation is substantiated by Neil Smith's (1984) recognition of the way in which institutions adapt themselves to capitalism. Smith examined new forms of industrialization, deindustrialization, regional decline, urbanization, geopolitics, nationalism and the rise of a new international division of labor in his book, Uneven Development. Smith argues that globalization processes "are not separate developments, but symptoms of a much deeper transformation in the geography of capitalism” [10]. Smith's theoretical insights frame the contemporary understanding of Brazilian higher education's interface with globalization. Smith's ideas are all the more important given that most international education research is focused on solving practical problems and does not yield much to a broader conceptual and systemic relationship with global capitalism. Cardoso also alluded to this trend toward applied research: "the world has changed, the nature of Capital has changed, the nature of work has also changed" [9]. In terms of Brazilian higher education, the nature and funding of "work" changed in favor of applied research and S.T.E.M.

\section{Innovating Brazilian Higher Education}

While President Cardoso's economic plan is recognized by many experts as the foundation of Brazil's current 
success as a BRICS country, there is current discord within the Brazilian higher education community about the unintended consequences of rapid economic restructuring on the federal university system. The nation-wide strike of federal university professors in 2012 reflected this discontent. The strike was in direct response to external market forces that served as a driving force in educational policy under presidents Lula and Rouseff. Like Cardoso, Lula and Rouseff originated in the political left and received wide support from intellectuals in the Brazilian academic community. Lula and Rouseff furthermore continued Cardoso's economic agenda and acknowledged that the competitiveness of the Brazilian economy no longer depended on a five-hundred year tradition of natural resource exports but instead must move into S.T.E.M. research and related spin-off industries. Their support of applied sciences over other traditional social sciences and humanities altered a decades-long academic culture of egalitarianism into one of disproportionate funding and S.T.E.M. favored supply-demand competition.

Brazilian higher education's move to a supply-sided economics culture can be observed in three stages. Stage 1 (1994-2002) began with Cardoso's post-dictatorship institutional economic reforms. Phase 2 (2003-2012) correlated with Lula's national economic plans to transform the Brazilian national economy into a BRICS power, which required the expansion of the middle-class, improvements in literacy and malnutrition among the low-income, and expanded university enrollments. Phase 2 also bore witness to the growth of new forms of higher education, such as the Support Program for the Restructuring and Expansion of Federal Universities (REUNI), distance learning, the Open University of Brazil, and other applied sciences—all of which received additional subsidies from Brasília.

The pressure for applied sciences to quickly produce research in a globally competitive arena also transformed the way in which academics from non-S.T.E.M. fields in the social sciences and humanities were to be assessed for programmatic and research funding. The culture of applying scientific knowledge to practical problems permeated the social sciences and humanities, threatening not only traditional epistemologies in areas like economics and philosophy, but also the essence of academic autonomy. Disproportionate funding for S.T.E.M. disciplines pressured social scientists and humanities researchers to compete for federal monies through work that reflected a more practical wisdom rather than one situated in theoretical paradigms. Phase 3 (2011-present) took the culture of applied science to a global platform with the federal government's explicit intention to make Brazil a competitive economy based on S.T.E.M. innovation. Students and scholars were awarded through competitive scholarship programs, such as the BSMP, to study and/or research abroad with the intention to return with an expanded knowledge base for new forms of Brazilian innovation.

Table 1 demonstrates the degree to which S.T.E.M disciplines fare better than other social science, humanities, and the fine arts. This data reflects Brazil's gradual focus on applied sciences over the past decade and additionally establishes a context for the BSMP. Table 2 demonstrates Brazil's ranking in academic mobility to the United States, which was an outcome of the BSMP effort.

Table 1. Research funding for brazilian scholars.

\begin{tabular}{cccccccc}
\hline \multirow{2}{*}{ Knowledge area } & \multicolumn{7}{c}{ Investments in Ph.D. research (R\$ mil) } \\
\cline { 2 - 7 } & $\mathbf{2 0 0 0}$ & $\mathbf{2 0 0 2}$ & $\mathbf{2 0 0 4}$ & $\mathbf{2 0 0 6}$ & $\mathbf{2 0 0 8}$ & $\mathbf{2 0 1 0}$ \\
\hline Agricultural sciences & 14.31 & 14.18 & 13.26 & 13.49 & 17.50 & 21.17 \\
Biological sciences & 16.73 & 13.85 & 15.37 & 16.55 & 20.40 & 21.57 \\
Health sciences & 8.23 & 7.16 & 7.02 & 8.37 & 9.52 & 10.43 \\
Earth sciences & 14.28 & 13.31 & 15.59 & 15.99 & 19.94 & 21.75 \\
Humanities & 12.47 & 10.91 & 9.77 & 8.71 & 8.47 & 8.49 \\
Applied social sciences & 14.63 & 11.84 & 7.87 & 7.19 & 7.21 & 7.50 \\
Engineering & 20.07 & 19.71 & 18.78 & 18.07 & 20.00 & 21.97 \\
Linguistics, letters and arts & 11.93 & 9.80 & 8.49 & 7.40 & 7.47 & 6.65 \\
All major areas & 15.97 & 14.88 & 14.72 & 14.57 & 16.72 & 18.25 \\
\hline
\end{tabular}

Source: Reprinted with permission from the Brazilian Ministry of Science and Technology's National Council for Scientific and Technological Development [7]. 
Table 2. Ranking of brazilian student mobility to the US (Among the BRICS \& South Korea).

\begin{tabular}{|c|c|c|c|c|c|}
\hline Rank & Country & 2010/12 & $2011 / 12$ & $\begin{array}{c}2011 / 12 \\
\% \text { of Total }\end{array}$ & \% Change \\
\hline 1 & China & 157,558 & 194,029 & 25.4 & 23.1 \\
\hline 2 & India & 103,895 & 100,270 & 13.1 & -3.5 \\
\hline 3 & South Korea & 73,351 & 72,295 & 9.5 & -1.4 \\
\hline 14 & Brazil & 8777 & 9029 & 1.2 & 2.9 \\
\hline 25 & Russia & 4692 & 4805 & 0.6 & 2.4 \\
\hline
\end{tabular}

Source: Reprinted with permission from IIE Open Doors [1].

Brazil has never ranked among the top ten countries that send foreign students to the United States (Brazil ranked $14^{\text {th }}$ in 2012). According to data compiled by the IIE (Institute for International Education), 9029 Brazilian students studied in the United States during the 2012 calendar year [2]. This is an unprecedented number of Brazilians in the US given that in 2000 approximately 1000 Brazilians studied in American institutions. Both China and India ranked first and second place, respectively. The other BRICS cousin, Russia, ranks even lower than Brazil at $25^{\text {th }}$ place (4805 students) [2].

The BSMP, while not the only channel through which Brazilian students enroll in the United States, was a significant contributor to the increase in enrollments. The BSMP has presented an aggressive agenda to send 100,000 undergraduate students abroad, with at least 50,000 students going to American campuses over the next five academic years (and ultimately send American undergraduates to study abroad in Brazil). The Brazilian federal government will support 75,000 students while the other 25,000 will be underwritten by endowments from the private sector. The IIE reports that in the 2014-2015 academic year 63\% of BSMP students were in engineering, $13 \%$ in hard sciences, $7 \%$ in medical sciences, and the other $17 \%$ consisted of business, social sciences, and humanities [11].

When observed in a global context, it is evident that the BSMP is designed to strengthen Brazil's ties with its other large Western Hemisphere partner, the United States, and other national economies in the core of the global political economy (e.g., the European Union, Australia, and South Korea). The mobility program also serves as a competitive means to better position Brazil against Asian economic contenders (China, India, and South Korea) as a preferred trading partner with the United States. Brazil’s relative geography, language, and Western cultural traditions are closer to that of US than its Asian peers, placing the South American giant in a favorable position to attract foreign direct investment, joint-ventures, and bilateral research and innovation in science and engineering (e.g., Petroleum) with North America and Europe.

Paradoxically, the Brazilian economy was insulated from the 2008 global economic crash and achieved economic growth rates of up to seven percent per year. By 2014, these growth rates slowed three percent but the federal government continued to sponsor 100,000 full scholarships for the BSMP as a means for national and foreign industries to hire young Brazilians after graduation. Despite the BSMP being popular with young Brazilians, the 2013 urban riots, for example, reflected students' frustration over the rising costs of living, the rampant political corruption, and the federal subsidies to support the 2014 World Cup and the upcoming 2016 Olympic games. This spending was contradicted by the underfunded social and physical infrastructure endemic throughout the country. Dissatisfaction was realized by national labor strikes, turbulent street protests, and political controversy. Brazil's global ambition of "order and progress” was essentially stymied by national disquiet. Yet Brazil continued apace with its plans to reaffirm regional hegemony in Latin America and cement newer bilateral ties in the Pacific Rim, most notably with China. For example, Brazil's co-sponsorship of the New Development Bank (NDB) in July 2014, whose backing consists of other BRICS members (Russia, India, China, and South Africa), will serve as an alternative to the International Monetary Fund (IMF) and confirm Brazil's leadership among other emerging economies. While China will contribute the majority of reserves, Brazil is expected to match India and Russia with $\$ 18$ billion [12].

\section{Post-Graduate Expansion in Brazil}

Post-graduate education is another critical aspect of Brazil's hegemonic ambitions. Brasília, in-part, aims to accomplish this outcome through the National Plan for Postgraduate Programs (PNPG), which was launched in 2011. The PNGP is expected to operate through 2020 and has four explicit objectives: to assess post-graduate 
programs, to increase student enrollments, to internationalize academic programs through student and faculty exchanges, and to establish a "practical epistemology" of applied research over theoretical investigation. Brasília expects the PNPG to heighten the country's capacity to produce new forms of innovation and to attract more foreign direct investment (FDI).

The PNPG is a continuation of a long-term strategy to attract FDI, which grew from only a few million reais when the new currency was launch in 1994 to R\$70 million in 2010 [13]. The expansion of FDI was in direct relationship with Cardoso's economic reforms (Phase 1). FDI was weak for decades due to Brazil's protectionist policies, hyperinflation, and bureaucratic heavy fascist (Vargas) and military regimes. The Plano Real in 1994 opened Brazil to the world economy but in order for FDI to increase, the country needed to be known as a place of S.T.E.M. innovation. The S.T.E.M. funded programs are an effort to establish an infrastructure for future capitalist investment and development.

CAPES (Coordination for the Improvement of Higher Education Teaching Personnel) is one such foundation within the Ministry of Higher Education that provides research grants to doctoral candidates, pre-doctoral short-term programs, and post-doctoral research scholars. CAPES was founded in 1951 but has more recently taken on strategic importance with student mobility and PPPs. CAPES is criticized by some Brazilian academics that its partnership with PPPS costs the system more than what is financially gained. In particular, critics fear that the marriage of higher education with corporate interests will erode academic autonomy, transform campuses into scientific marketplaces, and convert disciplines into commodities of different financial worth. If realized, these concerns would compel researchers to generate a faster turn-around of applied studies in order to be funded.

Private sponsorship of academic activity is a recent phenomenon in Brazil in contrast to the United States and other higher education markets in East Asia (e.g., South Korea). The cynical response, however, is not simply culture shock but a collective retort from voices in the social sciences, humanities, and the fine arts to the degree global capitalism has infiltrated Brazilian higher education. Brazilian opponents argue that the capitalist transformation of higher learning represents a clear shift from the classical Humboltian university, which shaped the philosophy of federal universities fifty years ago, to one framed by an "intellectual Taylorism". Intellectual Taylorism replicates a business management method that emphasizes economic efficiency and quicker turnaround of profits, which translates into faster turn-around of applied research and results.

\section{Synthesis}

Brazilian higher education is now a part of global capitalism. The empirical data presented in this paper, when integrated with a critical political economy narrative, explain Brazilian higher education's interface with neoliberalism and hegemonic rise. While all BRICS countries are considered political and economic allies, they nonetheless compete against one another for global prominence, economic development, and technical innovation. They interact with the world's largest educational marketplace, the United States, which lies at the nexus of the global economy. The bilateral educational relations between Brazil and the United States consist of an important aspect to promote their hegemony in a multipolar world. English is now the international lingua franca of science, engineering, and business. Brazil's ties with American universities through academic mobility are crucial if the country is to be an innovator in the neoliberal economy. This hegemonic strategy poses ramifications against the social sciences, the humanities, and fine arts while the S.T.E.M. disciplines emerge as clear winners.

There are advantages to Brazil's global engagements. The BSMP, for example, offers tangible benefits to students, researchers, universities, and the Brazilian government. From a student's perspective, the most obvious learning objective of the BSMP is the transformational change among Brazilian students who engage in meaningful intercultural exchange. Studying abroad is one of the most powerful experiences that a young adult can have during the formative years of her or his professional life. The potential for Brazilians to broaden their intellectual horizons while making lifelong friendships and professional connections is in many respects invaluable. Similar exchange benefits exist for tenured faculty within Brazilian federal universities. Yet there are pitfalls in Brazil's long-term endeavors with international applied research and innovation. Disproportionate funding in favor of S.T.E.M. has generated low morale and frustration among the faculty, as observed in 2012's national strike. Lower funding awards in the social sciences, humanities, and the fine arts could also impact new research on society, economics, and culture. The liberal arts play a critical role in a globally interconnected world given they shed light on the dimensions of interrelated peoples and cultures. S.T.E.M. cannot give a holistic explanation of our world. 
Brazil's ambition to expand applied research and S.T.E.M. innovation is also complicated by global, national, and local interests. The current dynamics of Brazilian university politics result from the external economic pressures to compete, produce, and generate results in a fast-paced knowledge-driven economy. There are also national political interests at play, most notably between Brazil and the United States. The launch of the BSMP was intentionally directed to serve both the interests of the Brazilian and American economies. The scholarship program was not exclusively rooted in the transformation of young adults' lives through education abroad. The BSMP is instead a Brasília-oriented economic stimulus package designed to boost S.T.E.M. related research, industry, and global prominence. The Brazilian government, along with private industry, intends to spend billions of reais (through taxes and PPPs) over the next few years to foster intellectual social capital and advance the infrastructure and innovation needs of a growing economy.

Brazil's endeavor to have global prominence in "a post-American world”, to use Zakaria’s (2011) terminology, will require more than just funding thousands of Brazilian university students to study abroad for one year [14]. Brazil must find a way to absorb its returning talent into its national economy. Brazil is faced with the serious task of being able to provide its students with employment after their intercambio ends. Brazil's national economy must be able to accommodate its returning students into formal employment if the country is to further its hegemonic agenda. With respect to Brazilian academic mobility, special attention must be given to the unintended consequences of broad-stroked S.T.E.M. scholarship schemes on other relevant disciplines in the social sciences, humanities, and arts.

There is also a direct market-related consequence among government agencies, private enterprise, and students with regard to perceiving the social sciences, humanities, and arts as having a lower "value" than those in the S.T.E.M. related disciplines. This socially constructed idea ultimately translates into the uneven funding of curricula, research, and salaries. Teixeira (1998) reminds us that academia is an indispensable institution inherent to society, without which individuals have no autonomy and are unable to think for themselves [15]. Hence, the liberal arts has a formative role in twenty-first century globalization and undermining them would be detrimental to Brazil’s social responsibilities, cultural morals, and artistic contributions at home and abroad.

\section{References}

[1] NAFSA International Educators Association (2012) Economic Impact Study. http://www.nafsa.org/_File/_/eis2012/usa.pdf

[2] Institute of International Education (2012) Brazil Science without Borders. http://www.iie.org/Programs/Brazil-Science-Without-Borders/

[3] Gertz, W.L. (2009) American Institute for Foreign Study. http://www.aifsfoundation.org/pdf/gertz_forward_globalmobility.pdf

[4] US Department of Commerce (2012) U.S.-Brazil 21 Summit Data Meeting Notes, Washington DC.

[5] Brazilian Institute for Geography and Statistics (IBGE) Demographic Data Reports (2104) http://www.ibge.gov.br/home/

[6] United Nations Statistical Division (2012) http://unstats.un.org/unsd/databases.htm

[7] Lima, M. (2012) Affirmative Action in Brazil. ReVista: Harvard Review of Latin America, 12, 64-67.

[8] Harvey, D. (1996) Justice, Nature, and the Geography of Difference. Blackwell Publishers, Oxford.

[9] Cardoso, F.H. (2001) Charting a New Course: The Politics of Globalization and Social Transformation. Rowman and Littlefield, Lanham.

[10] Smith, N. (1984) Uneven Development: Nature, Capital, and the Production of Space. The University of Georgia Press, Athens.

[11] Institute of International Education (2014) Brazilian Scientific Mobility Program. Host Institution Webinar Document, New York.

[12] Thomson Reuters (2014) The Knowledge Effect. http://blog.thomsonreuters.com/index.php/tag/brics/

[13] Brazilian Institute of Applied Research (IPEA) (2012) Meeting Notes.

[14] Zakaria, F. (2011) The Post-American World (Release 2.0). W.W. Norton \& Company, New York.

[15] Teixeria, A. (1998) Educação e Universidade. Editora UFRJ, Rio de Janeiro. 